\title{
Climate Proof Fresh Water Supply in Coastal Areas and Deltas in Europe
}

\author{
Ad Jeuken $^{1} \cdot$ Mette Termansen $^{2} \cdot$ Marco Antonellini $^{3}$ • \\ Theo Olsthoorn ${ }^{4} \cdot$ Eelco van Beek ${ }^{1,5}$
}

Published online: 23 December 2016

(C) The Author(s) 2016. This article is published with open access at Springerlink.com

In the near future, climate change will likely increase pressures on transition zones such as deltas and coastal areas (IPCC, 2013). This special issue focuses on how to "climate proof" these zones with special concerns for the stresses stemming from droughts and salinization. Coastal zones and Deltas are under pressure worldwide. High water demand in these regions put pressure on the availability of freshwater resources and on coastal ecosystems. This leads to problems like water shortage, overexploitation of groundwater resources, saltwater intrusion, and degradation of wetlands. Economic growth, population increase, and climate change may potentially intensify these problems. This, therefore, is of strategic importance for Europe, which has a long coastline where many human activities are concentrated. Coastal aquifer development is often intensive and prone to induce salinization because of seawater intrusion, up-coning of deep saline water, and residual salinity in aquitards (Custodio 2010). Severity and frequency of droughts appear to have increased in the southern European countries. Minimum river flows are projected to decrease significantly not only in southern and southeastern Europe, but also in many other parts of the continent, especially in summer (EEA 2012). The Mediterranean region is particularly stressed (e.g. Giorgi 2006), due to the combined effect of rising sea levels, increased water demand due to global warming, and reduced aquifer recharge.

In this special issue, local impacts and responses to the challenges described above are discussed in seven papers with case studies from the Netherlands, Spain, Portugal and Greece.

Ad Jeuken

Ad.Jeuken@Deltares.nl

Deltares, Delft, The Netherlands

2 Aarhus University, Aarhus, Denmark

3 University of Bologna, Bologna, Italy

4 Delft University, Delft, The Netherlands

5 Twente University, Enschede, The Netherlands 
These papers are functional in

- representing and demonstrating a wide range of tools to assess risk of fresh water shortage under climate change at both local (Stofberg et al., 2016) and regional scale (Stigter et al., 2015, Giannikopouloua et al., 2015, and Iglesias et al., 2015),

- providing practical examples of how to systematically compare different adaptation strategies (Giannikopouloua et al. 2015) and socio-economic development scenarios (Stigter et al., 2015).

- exploring novel methods to develop resilient, robust and flexible adaptation plans (Thissen et al., 2015) to account for a range of future developments (Stigter et al., 2015)

- $\quad$ and showing that adoption of new technologies such as presented by Zuurbier et al., 2016 and inventoried by Iglesias et al.. Iglesias et al., 2015 depend mostly on the risk perception and the confidence in these technologies (Veraart et al., 2016), which in turn is influenced by demonstrated success in terms of reliability and the costs-benefits ratio (Veraart et al., 2016 and Zuurbier et al., 2016)

Veraart et al. (2016) evaluate the socio-economic factors that determine the wider use of adaptation measures at farm level in a few pilot studies in the Southwestern part of the Netherlands. Water availability during the agricultural growing season is expected to decrease because of an expected increase in freshwater demands and a changing climate and is expected to affect agricultural production. A survey among farmers was used to analyze drought risk perception and willingness to invest in new innovative technologies for water buffering. The survey was complemented by feasibility studies at three pilot locations. The main insights of the paper are, i) that farmers in the area are not wellinformed about actual drought risk figures, ii) that the survey respondents were pessimistic about the wider implementation of the investigated technologies but that confidence in innovative measures increased amongst participants during the pilots and iii) that reliability of the freshwater supply and supportive legislation are the most decisive socioeconomic factors for a future investment in additional freshwater supply for farmers in this region. Furthermore, the study showed that farm type and crop choices had a significant influence on the benefits of the technologies.

Stigter et al. (Stigter et al. 2015) present a combined assessment of the potential impacts from climate change (CC) and socioeconomic development (SED) on the most important aquifer in the south of Portugal. The goal is to understand how CC and SED affect the currently large pressures from water consuming and contaminating activities, predominantly agriculture. The novelty of the study lies in the development of SED scenarios using combination of bottom-up and top-down methods in a collaborative way with farmers and institutional stakeholders in the water sector. Groundwater use was quantified for each scenario. Together with the recharge scenarios, they were used to model their individual and joint impacts on groundwater levels and discharge rates into a coastal estuary. The study clearly reveals that the desired scenario of growth and modernization of agriculture is unsustainable and would call for considerable adaptation efforts. The results thus reveal that $\mathrm{CC}$ in the region will dynamically interact with economic factors, and going one step beyond, $\mathrm{CC}$ could be directly integrated as a constraint in the development of SED scenarios. In the authors' view the method presented contributes in an encouraging manner to a more holistic and trans disciplinary approach to water management, by allowing a more plausible identification of what (and if) adaptation measures are needed. 
Iglesias et al. (2015) present another illustrative case for the Mediterranean area in which traditional agricultural practice, in this case rice production in coastal wetlands is threatened as freshwater supply is deteriorating at an unprecedented rate. The authors explore flexible adaptation options to climate change in the Donana wetlands in Spain. Several policy options for the improvement of agricultural water management were derived from stakeholder views framed according to the local environmental, social and policy context. Results suggest that perception on the potential role of new water infrastructure and farming subsidies dominates the view of local communities. The choices of the stakeholders were simulated with an agrohydrologicalmodel toquantify the effectsin terms of additional water availability for the rice farming. The paper shows that the in this way quantitative information provided during the study shaped the final adaptation options developed.

Giannikopouloua et al. (2015) propose a comprehensive method for an economic riskbased assessment and prioritization of long-term drought mitigation options in order to support decision making for drought planning. The assessment combines water balance modeling, hazard analysis, and risk and cost effectiveness analysis. The method is applied to the Greek island of Syros, a drought-prone area with recurring water scarcity problems due to agriculture and domestic water use. The proposed approach allows an improved understanding of drought-related risks by following a probabilistic analysis of drought impacts under different adaptation scenarios. Six adaptation strategies are compared in terms of contribution to future drought risk reduction using three criteria: risk, vulnerability and benefit-cost ratio. In contrast to the study by Stigter et al. (2015), Giannikopoulou et al. focus on the comparative risk assessment of adaptation options rather than on impacts under future uncertainties. In doing so they show the power of a systematic risk-based assessment of mitigation options coupled to the economic system in supporting decision makers.

Zuurbier et al. (2016) evaluate concrete innovative subsurface water technologies (SWT) that can provide solutions to manage freshwater resources in the subsurface. This is done by either actively increasing the amount of stored subsurface water or by protecting fresh water wells against salinization. The innovations are built upon existing techniques such as Aquifer Storage and Retrieval (ASR) but provide the users with much more control of their fresh water buffer under challenging circumstance like in salinizing deltas. By means of extensive field pilots and model exercises it is shown that the SWT can be used to deal with hydrogeological problems like seawater intrusion, upconing, and bubble drift during ASR and have significant economic benefits. At the same time these new technologies are sporadically applied to date. The authors argue that prolonged SWT testing in the current pilots, replication of SWT in other areas worldwide, and the development of technical and non-technical support tools are required to facilitate potential end-users in investment decision making and SWT implementation.

Stofberg et al., 2016 provide an extensive overview of analytical modeling tools to simulate and quantify the dynamics of fresh water lenses and its effects on the root zone of crops or the natural vegetation. These tools help appraising the hazard of fresh water lenses disappearing from the Dutch coastal regions. The analytical models also give a basis to identify where the lenses may disappear periodically and in which coastal areas this risk is largest. The results obtained and the procedure followed by Stofberg et al. may assist in water management decisions and choosing prioritization strategies leading to a secure/robust fresh water supply on a national to regional scale. The methodologies presented are also relevant and may be adapted to other European regions where coastal polders and dune systems are present as, for example, in France, Spain and the Adriatic Italian coast. 
Thissen et al. (2015) stress the need to take into account the fact that the future is highly uncertain and present three different approaches to fresh water supply planning under uncertainty in case studies in the Netherlands: a resilience approach, oriented to (re) designing fresh water systems in such a way that they will be less vulnerable, resp. Will be able to recover easily from future disturbances; a system robustness approach, oriented to quantitative assessment of system performance for various system configurations (adaptation options) under a range of external disturbances, and an exploratory modeling approach, developed to explore policy effectiveness and system operation under a very wide set of assumptions about future conditions. The examples shown are still rather conceptual and will need further operationalization. Some useful suggestions are however given how and under what circumstances to use the various methods. For example the presented resilience approach is recommended in an early stage of assessing a wide set of stakeholder options while the system robustness approach is recommended for quantitative analysis of one particular climate stressor. For all methods the outcome is however strongly dependent on whose perspective is guiding the scientific assessment and who is and is not responsible for adaptation.

Open Access This article is distributed under the terms of the Creative Commons Attribution 4.0 International License (http://creativecommons.org/licenses/by/4.0/), which permits unrestricted use, distribution, and reproduction in any medium, provided you give appropriate credit to the original author(s) and the source, provide a link to the Creative Commons license, and indicate if changes were made.

\section{References}

Custodio E (2010) Coastal aquifers of Europe: an overview. E Hydrogeol J 18:269. doi:10.1007/s10040-0090496-1

EEA (2012) Climate change, impacts and vulnerability in Europe 2012 An indicator-based report. EEA Report No $12 / 2012$

Giannikopouloua AS, Gada FK, Kampragoua E and Assimacopoulos D (2015) Risk-based assessment of drought mitigation options: The case of Syros Island, Greece (this issue)

Giorgi F (2006) Climate change hot-spots. Geophys Res Lett 33:L08707

Iglesias A, Sánchez B, Garrote L, López I (2015) Towards adaptation to climate change: water for rice in the coastal wetlands of Doñana, Southern Spain (this issue)

IPCC (2013) Climate Change 2013; 5th assessment report. The physical science basis

Stigter TY, Varanda M, Bento S, Nunes JP, Hugman R (2015) Combined assessment of climate change and socio-economic development as drivers of freshwater availability in the South of Portugal (this issue)

Stofberg SF, Oude Essink GHP, Pauw PS, de Louw PGB, Leijnse A, van der Zee SEATM, (2016) Fresh water lens persistence and root zone salinization hazard under temperate climate (this issue)

Thissen W, Kwakkel J, Mens M, van der Sluijs J, Stemberger S, Wardekker A, Wildschut D (2015) Dealing with uncertainties in fresh water supply: Experiences in the Netherlands (this issue)

Veraart JA, van Duinen R, Vreke J (2016) Evaluation of socio-economic factors that determine adoption of climate compatible freshwater supply measures at farm level: a case study in the southwest Netherlands (this issue)

Zuurbier KG, Raat KJ, Paalman M, Oosterhof AT, Stuyfzand PJ (2016) How subsurface water technologies (SWT) can provide robust, effective, and costefficient solutions for freshwater management in coastal zones (this issue) 